\title{
Um olhar no Geoparque Seridó à luz do desenvolvimento e do capital social
}

A look at the Seridó Geopark the light of development and social capital Una mirada en el Geoparque Seridó la luz del desarrollo y el capital social http://dx.doi.org/10.18472/cvt.18n1.2018.1243

Cristiane Soares Cardoso Dantas Gomes < crisscdantas@gmail.com > Universidade Federal do Rio Grande do Norte (UFRN), Natal, RN, Brasil

Francisco Fransualdo de Azevedo 〈 ffazevedo@gmail.com > Universidade Federal do Rio Grande do Norte (UFRN), Natal, RN, Brasil

Marcos Antonio Leite do Nascimento 〈marcos@geologia.ufrn.br〉 Universidade Federal do Rio Grande do Norte (UFRN), Natal, RN, Brasil

CRONOLOGIA DO PROCESSO EDITORIAL

Recebimento do artigo: $24-\mathrm{fev}-2016$

Aceite: 04-jan-2018

FORMATO PARA CITAÇÃO DESTE ARTIGO

GOMES, C. S. C. D.; AZEVEDO, F. F. de.; NASCIMENTO, M. A. L. do. Um olhar no Geoparque Seridó à luz do desenvolvimento e do capital social. Caderno Virtual de Turismo. Rio de Janeiro, v. 18, n. 1, p. 116-132, abr. 2018.

REALIZAÇÃO

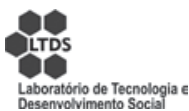

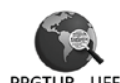

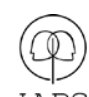

IABS
APOIO INSTITUCIONAL

COPPE

UFR]

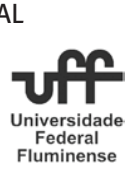

EDIÇÃO

PATROCÍNIO

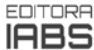




\title{
RESUMO
}

O contexto social é moldado por diferentes interesses e, por essa razão, o Estado necessita atuar na intermediação dos conflitos a fim de imperar o bem comum. É por meio das políticas públicas que o Estado atua para harmonizar os conflitos. Independente do setor há uma política pública para nortear suas ações e o mesmo acontece com o Turismo. Uma das formas de materializar as políticas públicas são os projetos, e o Geoparque Seridó pode ser beneficiado. Assim, o objetivo do trabalho é analisar a contribuição do geoparque para o fortalecimento do capital social seridoense. Para atingir tal finalidade, utilizou-se a pesquisa documental e bibliográfica para permitir uma reflexão do objeto estudado, caracterizando o viés qualitativo. Dessa forma, identificou-se que o capital social seridoense pode ser fortalecido por meio do geoparque, em razão do estímulo à participação dos atores sociais no que se refere à construção das ações no âmbito deste, resultando em um amadurecimento cívico desses atores, o que acarretará na reverberação da participação em outras esferas da sociedade seridoense, consolidando ainda mais o seu capital social.

Palavras-chave: Estado. Políticas Públicas. Geoparque Seridó. Desenvolvimento. Capital social.

\begin{abstract}
The social context is shaped by different interests and for this reason, the state needs to act in the intermediation of conflicts in order to rule the common good. It is through Public Policies that the State acts to harmonize conflicts. Regardless of the sector, there is a public policy to guide its actions, and so does Tourism. One of the ways to materialize the public policies are the projects, and the Serido Geopark can benefit. Thus, the objective of this work is to analyze the contribution of the Geopark to the strengthening of Serido Social Capital. In order to achieve this purpose, we used documentary and bibliographic research, to allow a reflection of the object studied, characterizing the qualitative bias. Thus, it was identified that the Serido social capital can be strengthened through the geopark, due to the stimulation of the participation of the social actors in the construction of the actions within the geopark, resulting in a civic maturation of these actors, the which will lead to the reverberation of participation in other spheres of Serido society, further consolidating its Social Capital.
\end{abstract}

Keywords: State. Public Policy. Serido Geopark. Development and Capital.

\section{RESUMEN}

El contexto social es moldeado por diferentes intereses y por esa razón, el Estado necesita actuar en la intermediación de los conflictos a fin de imperar el bien común. Es por medio de las Políticas Públicas que el Estado actúa para armonizar los conflictos. Independiente del sector hay una política pública para orientar sus acciones y lo mismo sucede con el Turismo. Una de las formas de materializar las políticas públicas son los proyectos, y el Geoparque Seridó puede ser beneficiado. Así, el objetivo del trabajo es analizar la contribución del Geoparque para el fortalecimiento del Capital Social seridoense. Para alcanzar tal propósito, se utilizó la investigación documental y bibliográfica, para permitir una reflexión del objeto estudiado, caracterizando el sesgo cualitativo. De esta forma, se identificó que el capital social seridoense puede ser fortalecido por medio del geoparque, en razón del estímulo a la participación de los actores sociales en lo que se refiere a la construcción de las acciones en el ámbito del geoparque, resultando en una maduración cívica de esos actores, que acarreará en la reverberación de la participación en otras esferas de la sociedad seridaense, consolidando aún más su Capital Social.

Palavras clave: Estado. Política Pública. Geoparque Seridó. Desarrollo. Capital Social. 


\section{INTRODUÇÃO}

O Estado executa suas ações em relação a determinados setores por meio da formulação de políticas públicas com objetivo de intermediar conflitos e interesse nas esferas da sociedade. Porém, como se está inserido em uma lógica capitalista, em que as questões econômicas são mais enaltecidas que as demais áreas, muitas vezes, a elaboração de uma política é direcionada ao atendimento de necessidades de setores específicos.

Entretanto, mesmo nesse cenário, é primordial o desenvolvimento de tais políticas para nortear as diretrizes dos setores aos quais estas são destinadas. O turismo é um setor que também apresenta suas políticas públicas, porém, sua relevância passou a imperar em função dos seus efeitos e impactos econômicos. A materialização de tais medidas ocorre por meio de projetos, programas e leis.

Uma medida que pode ser contemplada por uma política pública de turismo é o projeto Geoparque Seridó. Um geoparque é um atrativo turístico com ênfase nos aspectos geológicos, com elementos da geodiversidade (meio físico e meio abiótico) de singular valor, seja do ponto de vista científico, educativo e turístico. Este projeto a geoparque, localizado no estado do Rio Grande do Norte, na região do Seridó, abrange seis municípios (Lagoa Nova, Cerro Corá, Currais Novos, Acari, Carnaúba dos Dantas e Parelhas).

Portanto, o objetivo do trabalho é mostrar como o capital social pode ser fortalecido por meio do Geoparque Seridó. Logo, a pesquisa está estruturada em eixos teóricos, como o papel do Estado e a elaboração de políticas públicas, políticas públicas de turismo, apresentação da proposta do Geoparque Seridó e desenvolvimento local, participação social, fortalecimento do capital social seridoense por meio deste projeto (Geoparque Seridó), que será detalhada a seguir.

\section{O PAPEL DO ESTADO E A ELABORAÇÃO DE POLÍTICAS PÚBLICAS}

A sociedade é permeada por diferentes interesses que ocasionam situações de divergências e conflitos. Por essa razão, o Estado é considerado como responsável de mediar esforços para manutenção da ordem, segurança e bem-estar em uma sociedade.

Uma das ideias gerais a respeito do Estado é que este tem como fim o bem comum dos seus cidadãos. Essa premissa pode ser comprovada por Poulantzas (1986) em que menciona o Estado como um fator de coesão dos diferentes níveis de formação social, com a finalidade de regular o equilíbrio. Oliveira (2006, p. 11) ressalta que a concepção de que o "bom governo" é todo aquele no qual os detentores do poder governam para o bem de todos (e não para o próprio bem ou para o bem de alguns).

É interessante destacar que Carnoy (1990 apud Oliveira 2006) menciona que o Estado tem sua gênese justamente na necessidade de controlar conflitos entre os diferentes interesses, surgindo como resposta à necessidade de mediar os conflitos de classe, com o intuito de manter a ordem. Partindo das análises expostas, é interessante abordar o conceito ao qual se atribui a palavra Estado. 
Pereira (1995, p. 86) salienta que "o conceito de Estado é impreciso na ciência política”. Evidencia o quanto é comum confundir Estado com governo, com regime político ou até mesmo com sistema econômico. O conceito de Estado para este trabalho assemelha-se com o do autor supracitado, quando descreve que "O Estado é parte de uma sociedade. É uma estrutura política e organizacional que se sobrepõe à sociedade ao mesmo tempo em que dela faz parte”. (PEREIRA, 1995, p. 86).

Mas, a visão de Estado nem sempre foi a mesma. Houve momentos que teóricos (Durkheim, Hobbes e Max) abordavam tal temática com diferentes enfoques. Vale ressaltar de forma sucinta essas ópticas diferenciadas de Estado. Para o sociólogo, psicólogo e filósofo Durkheim, o Estado é um organizador da vida social. A sociedade é submetida a uma autoridade e esta não depende de autoridade superior. (SACCOL, 2012).

O inglês Thomas Hobbes se reportava ao Estado como instituição para regular as relações humanas. Este seria o guardião da soberania absoluta. É o que Putnam (1996) enfatiza como a coerção de um terceiro na óptica de Hobbes. E que somente por meio da instauração desse Estado os homens abandonariam o estado de natureza e passariam a viver em sociedade.

Entretanto, uma maior ênfase será dada à óptica marxista do Estado, visto que a sociedade está permeada por relações de poder, em que esse poder configura a sociedade e influencia a tomada de ações e decisões na esfera estatal em detrimento ao favorecimento de classes.

Apesar da finalidade do Estado como exposto acima, a discussão teórica difere da prática, e, de certa forma, a atuação do Estado, em alguns contextos, não diverge da óptica marxista do Estado, já que alguns utilizam da força do Estado para auferir benefícios próprios, secundarizando os benefícios dos demais.

Bobbio (1988) salienta que Marx considerava o Estado como um instrumento de domínio dos interesses da classe economicamente mais forte, enfatizando o Estado como uma expressão política de dominação de classe a serviço da classe economicamente mais forte, não representando o interesse comum ou a vontade geral.

A crítica ao Estado na óptica marxista fica clara ao mencionar que "O Estado Moderno não passa de um comitê que administra os negócios da classe burguesa como um todo” (MARK; ENGELS, 1998). O que traduz um caráter classista que tem a finalidade de manter a dominação e as relações de produção.

A relação de dominação se configura quando o Estado se manifesta como uma instituição acima de todas as outras, cuja função é de assegurar e conservar a dominação e a exploração da classe burguesa sobre o proletariado. No contexto marxista, a burguesia enquanto classe social adquire um acúmulo de riqueza e poder e essa mesma classe possui um papel importante nas relações mercantis.

Conforme Souza (2010, p. 37), "O Estado é sempre uma instância em desfavor dos trabalhadores, já que pode regular, mas nunca extinguir, essa mediação fundamental: a exploração do trabalho pelo capital". Ressalta ainda:

O Estado é uma esfera a favor das classes dominantes desde seus primórdios, nas sociedades escravistas da antiguidade. Surgiu para proteger os interesses da classe dominante e controlar as revoltas dos escravos. Assim, a burguesia, regida pela lógica de acumulação de capital, lança milhares de seres humanos em uma situação de pobreza extrema (SOUZA, 2010, p. 37).

Esse contexto marxista de Estado pouco difere do contexto atual. O Estado deveria se portar como ente neutro, concentrando seus esforços para um processo dialético para com a sociedade, na busca do bem 
comum. Mas, há de se concordar com Putman (1996), quando este coloca que os que dirigem o Estado usam tal força em proveito próprio à custa do resto da sociedade.

Em uma sociedade pressupõe a existência de necessidades coletivas composta por interesses diferenciados e possivelmente antagônicos, o que carece de uma intermediação que pondere tais interesses. Entretanto Vidal (2011) salienta que:

Nem toda necessidade coletiva consegue se tornar uma necessidade pública, ou seja, receber a chancela estatal e originar políticas públicas e ações governamentais correspondentes, ainda que seja concreta e reclamada por expressivos segmentos da sociedade. Em contrapartida, nem todo atendimento efetivo, pelo Estado, de uma necessidade pública tende a contribuir para o bem-estar pleno da sociedade, de modo geral, nem mesmo de sua maioria. (VIDAL, 2011, p. 2)

Tal ponto de vista pode ser explicado pela seguinte razão: por mais que o Estado tenha como atribuição o atendimento das necessidades de uma coletividade, essa necessidade não será agraciada em sua plenitude, posto que, o sistema capitalista é o que impera em um contexto global e este se reveste de contradições, exclusões e oposições de classes. Em razão desse contexto, o Estado, quanto ao direcionamento dos resultados da produção e aspectos sociais, é voltado ao atendimento de interesses específicos.

Associado ao exposto acima, Sousa (1995 apud AZEVEDO; FIGUEIREDO; NÓBREGA; MARANHÃO, 2013, p. 20) aponta os principais problemas que impossibilitam o exercício do trabalho institucional do Estado:

a) Corporativismo, cuja lógica é autoproteção dos funcionários em detrimento dos objetivos finalísticos das instituições;

b) Morosidade nas decisões;

c) Ausência de política de qualificação, inibindo a formação de quadros competentes e provocando cortes e fluxos de informações;

d) Tomada de decisões orientada por critérios clientelísticos ou afetivos;

e) Reduzida flexibilidade das ações, não permitindo a incorporação de elementos que favoreçam os processos avaliativos.

Apesar desse contexto adverso, o Estado, ainda assim, tem como atribuição organizar a vida em sociedade nas diferentes dimensões, econômica, social, política, entre outras. Destarte, o Estado precisa agir e, para tal ação, utiliza-se de políticas públicas para atender aos anseios de seus cidadãos.

A política pública, enquanto área do conhecimento e disciplina, conforme Souza (2003), desponta nos EUA, rompendo com a tradição europeia na qual os estudos sobre o tema concentravam-se na análise sobre o Estado e suas instituições. A área contou com grandes contribuições de H. Laswell, H. Simon, C. Lindblom e D. Easton, considerados fundadores da área.

Quando se fala de política pública, a ideia que está por trás nos remete a questões de coletividade, ações que podem ser desenvolvidas para contemplar os interesses de uma sociedade. Resultados da ação de um Estado. Entretanto, há certa confusão quando se relaciona o "público" como exclusividade do Estado. Porém isso tem uma explicação. Coutinho (2015) menciona que em função da crise vivenciada pelo capitalismo no final do Século XIX, fragilizando com a economia mundial na década de 1930, o Estado intensificou a produção de bens públicos, o que resultou na associação do bem público pertencente ao 
Estado.

As políticas públicas são direcionadas para atendimento de interesses, preferências em relação à atuação ou não do Estado sobre determinadas questões. Teixeira (2002, p. 2) traz a seguinte definição:

Políticas Públicas são diretrizes, princípios norteadores de ação do poder público; regras e procedimentos para as relações entre poder público e sociedade, mediações entre atores da sociedade e do Estado. São, nesse caso, políticas explicitadas, sistematizadas ou formuladas em documentos (leis, programas, linhas de financiamento) que orientam ações que normalmente envolvem aplicações de recursos públicos.

Essas políticas muitas vezes são vistas como uma resposta do Estado às demandas marginalizadas em uma sociedade. De certa forma, tais medidas exprimem a vontade daqueles que estão no poder. Entretanto, tais políticas sofrem intromissão dos mais diferentes setores da sociedade, pois cada um intervém em prol dos seus anseios e tenta barganhar determinada ação do governo a seu favor.

Autores como Frey (2000) mencionam as etapas sequenciais do agir público, ou seja, a fase de elaboração de uma política pública que seriam:

a) Definição de uma agenda: decisão do tema que deve ser inserido na pauta política atual;

b) Formação de agenda: processo de definir, considerar, aceitar ou rejeitar opções pelos formuladores;

c) Tomada de decisão: escolha entre as alternativas geradas durante a fase de formulação;

d) Implementação: estágio no qual programas e políticas são realizados;

e) Avaliação: processo de verificar os objetivos perseguidos e alcançados.

Apesar dessa sequência, os atores políticos não necessariamente se atêm a essa ordem. Mesmo diante da não obediência a tais pontos, a política pública, ainda assim, possui sua relevância. Como atuam nas mais diversas áreas, o turismo é contemplado por tal medida com a finalidade de orientar os objetivos e diretrizes em sua área. Portanto, uma descrição mais aprofundada sobre políticas públicas de turismo será tratada a seguir.

\section{POLÍTICAS PÚBLICAS DE TURISMO}

Assim como as demais áreas que necessitam de orientações para modificar a realidade, o turismo precisa de um alicerce para o desenvolvimento de suas ações em prol da atividade. Para que a atividade turística tenha uma expansão harmônica, é importante o papel das políticas públicas aplicadas ao setor. Estas se fazem necessárias até mesmo com a finalidade de permitir certo controle à atividade.

Azevedo, Figueiredo, Nóbrega e Maranhão (2013) ressaltam que as primeiras políticas públicas de turismo em âmbito mundial surgiram com a Organização Mundial de Turismo - OMT em 1975. Em termos de Brasil, a política de turismo apresenta períodos distintos. Antes de se adentrar nesse aspecto, é interessante uma abordagem na definição sobre políticas públicas de turismo.

Goeldner, Ritchie e McIntosh (2002, p. 294) definem políticas públicas de turismo como: 
Um conjunto de regulamentação, regras, diretrizes, diretivas, objetivos e estratégias de desenvolvimento e promoção que fornece uma estrutura na qual são tomadas as decisões coletivas e individuais que afetam diretamente o desenvolvimento turístico e as atividades diárias dentro de uma destinação.

As políticas de turismo nada mais são que um conjunto de medidas, ações e diretrizes tomadas pelos responsáveis do setor no intuito de permitir o direcionamento e organização da atividade. Azevedo, Figueiredo, Nóbrega e Maranhão (2013) ressaltam que é por meio dessas medidas que podem ser identificados obstáculos e que podem sanar problemas na esfera social, econômica e ambiental, com integração de ações para permitir o desenvolvimento da atividade turística.

Ao abordar o entendimento de uma política pública de turismo, verificam-se duas formas conforme expõe Beni (2006, p. 64), “de um lado uma visão de mercado que acredita que a partir dela podem-se obter resultados mais eficazes, e, por outro, a política funcionando como estratégia para o desenvolvimento harmonioso, estabelecendo limites e garantindo o atendimento às necessidades e expectativas da comunidade".

É válido salientar que as políticas públicas de um modo geral, como também as de turismo, estão condicionadas a pressões sociais e políticas, não só da sociedade, mas de setores que veem na prática da atividade meios de obterem lucro com sua exploração. É interessante que a política pública não seja concebida de forma isolada, mas sim com articulações e dinamismos em que as decisões tomadas sejam o início de um processo mais amplo.

Outro aspecto sobre as políticas públicas de turismo é que estas passaram a ser formuladas quando a atividade turística já acontecia, ou seja, só começaram a ter status de relevância quando produziram efeitos econômicos significativos, o que explica algumas ações imediatistas do setor.

É interessante que essas medidas sejam pensadas e articuladas de forma a promover uma melhor distribuição dos resultados da atividade, de ordem econômica e social, além de levar em consideração as peculiaridades de cada localidade em ações de planejamento do setor. Entretanto, a articulação de políticas públicas de turismo carece de um corpo técnico qualificado. E isso resulta em ações desconexas na execução e planejamento de atividades, assim como no turismo.

Apesar desses percalços, o cenário da política pública de turismo no contexto brasileiro passou por mudanças em cenários temporais diferenciados, como apontados em uma breve descrição a seguir:

1990-2002: Nesse período tem destaque o Plano Nacional de Municipalização do Turismo - PNMT, que tinha a finalidade de melhorar o produto turístico brasileiro por meio da conscientização dos municípios e seus habitantes sobre os benefícios econômicos do turismo, bem como a descentralização da atividade. Entretanto houve falhas, pois, como se presumia, falta de conhecimento das localidades e não foi realizada uma inventariação turística, queimou-se a primeira etapa do projeto. Beni (2006) ressalta conflitos entre os objetivos e a proposta do PNMT em razão do espaço geográfico brasileiro. Ainda nesse período, houve programas instituídos pelo governo federal, por meio da Embratur, como o Prodetur-NE, Prodetur-Sul, Prodetur-SE e Programa de Desenvolvimento do Ecoturismo na Amazônia Legal - Proecotur, além do programa Parques do Brasil, lançado pela Embratur em parceira com o Ibama, para utilização do potencial ecoturístico dos espaços naturais protegidos.

2003-2013: Cria-se o Ministério do Turismo e a área passa a ter uma estrutura e orçamento específico. É criado o CNTUR, como órgão colegiado de assessoramento superior, vinculado diretamente ao ministro 
de Estado com a função de propor diretrizes, fornecer subsídios e contribuir para implementação do Plano Nacional de Turismo. A Embratur passa a ser responsável pela promoção do País no exterior e pela elaboração de estudos e pesquisas para orientar as decisões e avaliar o impacto do turismo na economia nacional e formatar novos produtos e roteiros. Foram criados os fóruns de secretários estaduais para descentralizar a gestão da atividade. A atividade turística passa a ter uma abordagem de desenvolvimento regional, concretizada nos Programas de Regionalização do Turismo "Roteiros do Brasil" sob a égide do macroprograma 4 de estruturação e diversificação da oferta turística.

Apesar de o Ministério do Turismo possuir um aparato institucional com ferramentas para planejar o turismo com diretrizes que indicam o direcionamento e articulação do processo de regionalização, os estados e municípios enfrentam dificuldades para operacionalização desses programas, seja por falta de pessoas qualificadas e até mesmo o mau gerenciamento do turismo em algumas localidades.

Apesar das adversidades de articulação que atividade turística enfrenta, as políticas públicas são uma das formas de materializar programas, projetos e planos que devem contemplar as características dos estados, municípios e o interesse da comunidade. Diante dessa premissa, um projeto que poderia ser contemplado por meio de uma política pública seria o projeto Geoparque Seridó, que será melhor detalhado a seguir.

\section{GEOPARQUE SERIDÓ: UMA BREVE CARACTERIZAÇÃO}

Geoparque trata-se de um novo programa da Unesco (Global Geoparks), a exemplo dos programas do Homem e da Biosfera (Man and Biosphere - MAB Programme) e Patrimônio da Humanidade (World Heritage Programme), oficializado em 17 de novembro de 2015. Geoparque é um território com limites bem definidos e que apresenta um notável patrimônio geológico de importância internacional, nacional e/ou regional, ligado a uma estratégia de desenvolvimento sustentável. Integra locais de interesse geológico de especial valor científico, mas também educativo e/ou turístico, conhecidos como geossítios. A presença de valores ecológico, histórico ou cultural também se faz importante e juntos ao geológico permitem a realização de projetos educacionais e/ou turísticos. Esses espaços, por meio do geoturismo, atividade turística que tem nas feições geológicas seus principais atrativos, geram benefícios econômicos, além de educar as pessoas sobre a evolução do local e paisagem. (FARSANI; COELHO; COSTA, 2010).

A origem dessa iniciativa foi fruto de discussões entre os geólogos Guy Martini e Nickolas Zouros no $30^{\circ}$ Congresso Internacional de Geologia, realizado no ano de 1996 em Pequim durante o Simpósio sobre Proteção do Patrimônio Geológico. Essa iniciativa tinha a finalidade de promover o desenvolvimento territorial sustentável e que este fosse alcançado por meio da conservação e promoção do patrimônio geológico para fins científicos, educacionais e turísticos (NASCIMENTO et al., 2015).

Dessarte, quatro territórios (França, Grécia, Alemanha e Espanha), por meio de um importante programa europeu (LEADER+- Ligação entre Ações de Desenvolvimento da Economia Rural), resultado de uma política de desenvolvimento rural com a perspectiva de caráter inovador, cooperação e redes de parcerias, se uniram e iniciaram a troca de experiência com a intenção de proteger e promover o patrimônio geológico, além de desenvolver economicamente e sustentavelmente as localidades. O motivo que justificou a união desses territórios se deu pelo fato de serem áreas rurais que enfrentavam um declínio em seu desenvolvimento econômico, altos índices de desemprego e êxodo rural (ZOUROS, 2004). 
Dessa forma, esses quatro geoparques assinaram uma convenção que resultou no ano de 2000 na criação da Rede Europeia de Geoparques. A iniciativa, com o passar dos anos, culminou de forma positiva e o que antes começou com quatro geoparques, atualmente conta com 127 geoparques em 35 países.

A valorização dos geoparques ocorre porque promovem oportunidades de emprego, benefícios econômicos para as pessoas que vivem em suas áreas ou próximo a elas, seja por meio de criação de empresas locais, indústrias caseiras envolvidas com o geoturismo e seus geoprodutos. Além do mais, educam as pessoas sobre a promoção e valorização do patrimônio geológico, promove o fortalecimento da história local, seja por meio de registros existentes no meio físico, a exemplo de pinturas rupestres, e consolida a cultura por meio de lendas e mitos.

O Brasil é detentor de um potencial para criação de geoparques, em consequência da variedade geológica associada a aspectos ecológicos, culturais e arqueológicos. A Companhia de Pesquisa de Recursos Minerais - CPRM, por intermédio do Departamento de Gestão Territorial, lançou em 2006 o projeto Geoparques Brasil que tem como objetivo identificar áreas potenciais para criação de geoparques.

Entre as iniciativas de criação de geoparques no cenário brasileiro, encontra-se a do Geoparque Seridó. Segundo Alves (2007), a região do Seridó abriga uma natureza formada por rochas, trilhas, rios, açudes e vegetações rasteiras, com sítios arqueológicos e inscrições rupestres, oferecendo atrativos turísticos que a colocam em uma posição privilegiada.

O Geoparque Seridó está localizado na porção centro sul do estado do Rio Grande do Norte, envolvendo seis municípios: Cerro Corá, Lagoa Nova, Currais Novos, Acari, Carnaúba dos Dantas e Parelhas. A proposta contempla 16 geossítios conforme ilustra a Figura 1 a seguir.

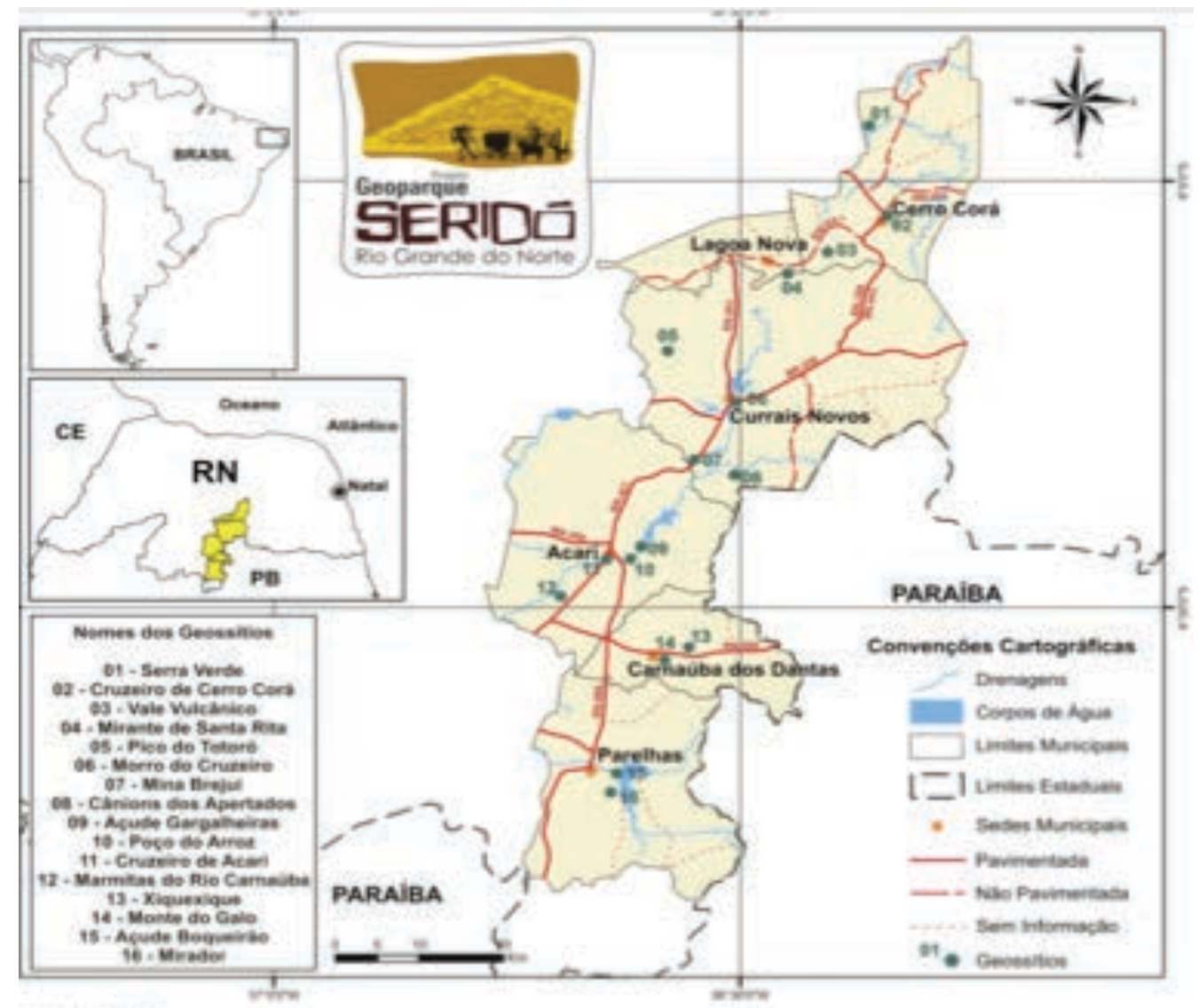


Figura 1 - Localização da área prop

Fonte: Medeiros

As fotos a seguir mostram um pouco do potencial científico, cultural, educacional e turístico que pode ser encontrado dentro da proposta do Geoparque Seridó:

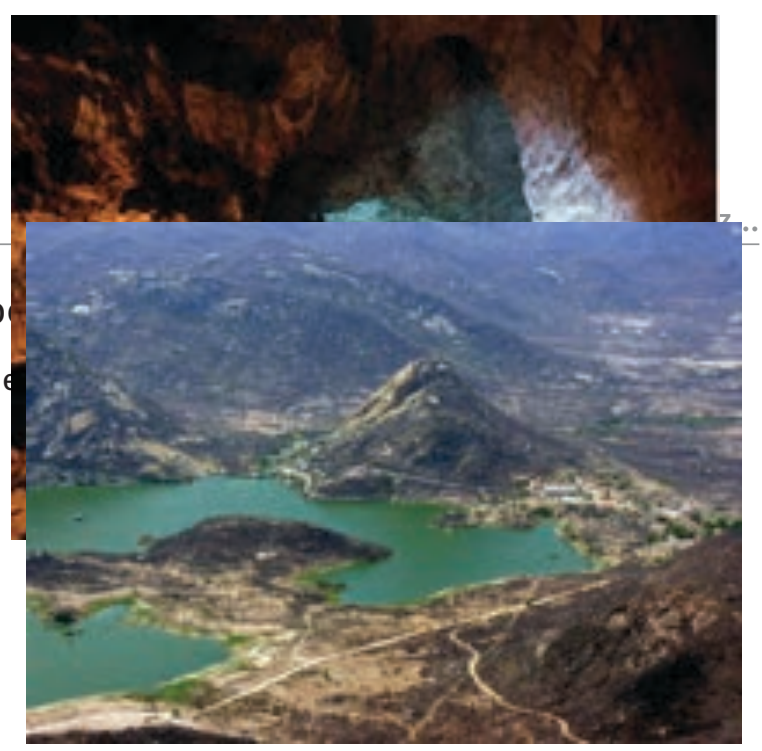

Figura 3 - Geossítio Açude Gargalheiras Acari/RN.

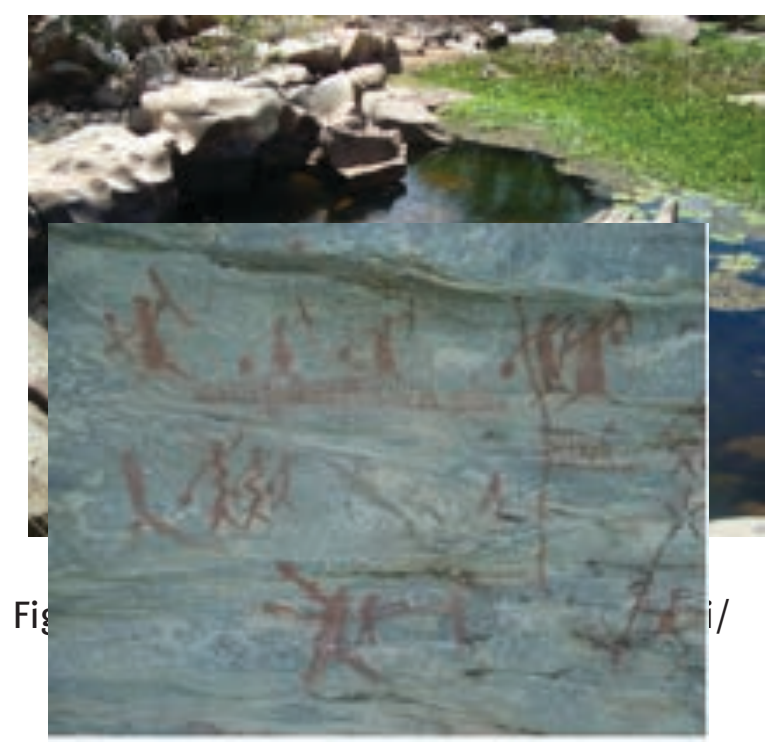

Figura 5 - Geossítio Xique-Xique em Carnaúba dos Dantas.

$\mathrm{Na}$ área que abrange a proposta do Geoparque
Seridó existe iniciativas ligadas à atividade turística, como o Polo Turístico do Seridó, que foi criado pelo governo do estado do Rio Grande do Norte por meio do Decreto No 18.429 , de 15 de agosto de 2005, bem como o Roteiro Seridó que foi fomentado pelo Sebrae/RN e a Setur/RN, em consonância com o Programa de Regionalização do Turismo promovido pelo Ministério do Turismo do Governo Federal.

Como os discursos sobre a temática de geoparques abrangem a questão do desenvolvimento que pode proporcionar para

as localidades em que estão inseridos, é válida uma reflexão sobre como o Geoparque Seridó pode ser um meio para o desenvolvimento e fortalecimento do capital social em seu território, como será detalhado a seguir.

\section{DESENVOLVIMENTO LOCAL E PARTICIPAÇÃO SOCIAL: UM ELO FORTALECEDOR PARA O CAPITAL SOCIAL SERIDOENSE POR MEIO DO GEOPARQUE SERIDÓ}


Ao fazer menção ao termo desenvolvimento, vincula-se este à questão do crescimento econômico, aumento da renda, ou seja, apenas ao viés economicista, o que resulta em uma visão limitada e restritiva do termo. Esse reducionismo econômico do desenvolvimento tem esse enfoque mais forte pelo contexto capitalista, em que os indivíduos e a natureza estão a serviço da economia, a ponto de serem vistos como mercadorias. Tal afirmação corrobora com a premissa de Max-Neef (1993) quando menciona que o mercado se torna um grande organizador da vida socioeconômica e o consumismo, valor essencial da sociedade.

A importância do crescimento econômico para o desenvolvimento não pode ser descartada, ele tem sim sua relevância, entretanto, a óptica do desenvolvimento não deve ser reduzida apenas a cifras monetárias.

Tal contexto é reforçado por Sen (2000), quando menciona o desenvolvimento como expansão das liberdades. Essa liberdade abordada pelo autor seria, além dos elementos econômicos, o acesso a aspectos sociais, como educação, saúde, segurança bem como participar em discussões e averiguações públicas. Esse desenvolvimento proposto pelo referido autor promove a liberdade.

Ainda para Sen (2000), essa perspectiva mais ampla de desenvolvimento removeria as principais causas de privação da liberdade: a pobreza, carência de oportunidades econômicas, negligência dos serviços públicos, negação de liberdade política e civil. A eliminação dessas privações repercutirá em uma melhoria social, reverberando na qualidade de vida e o bem-estar de uma sociedade. Essa perspectiva afirma-se quando o autor menciona:

O desenvolvimento tem de estar relacionado, sobretudo, com a melhoria da vida que levamos e das liberdades que desfrutamos. Expandir as liberdades que temos razão para valorizar não só torna nossa vida mais rica e mais desimpedida, mas também permite que sejamos seres sociais mais completos, pondo em prática nossas volições, interagindo com o mundo em que vivemos e influenciando esse mundo. (SEN, 2000, p. 29)

Logo, conforme salienta Sen (2000, p. 71)

Os meios e os fins do desenvolvimento exigem que a perspectiva da liberdade seja colocada no centro do palco. Nessa perspectiva, as pessoas têm de ser vistas como ativamente envolvidas, dada a oportunidade na conformação de seu próprio destino, e não apenas como beneficiárias passivas dos frutos de engenhosos programas de desenvolvimento.

Outro autor que complementa a perspectiva de desenvolvimento abordado por Sen (2000) é Max-Neef (1993) quando menciona que os fatores econômicos são apenas parte do processo de desenvolvimento. Para este autor, o desenvolvimento está pautado na compreensão da estrutura dinâmica do sistema econômico a partir da perspectiva da atenção às necessidades humanas básicas. O autor salienta que o desenvolvimento deveria ser feito para as pessoas, baseando-se em três pilares: na satisfação das necessidades humanas fundamentais, na geração de níveis crescentes de autodependência e na articulação orgânica entre o homem, a natureza e a tecnologia, visto que a chave do desenvolvimento se encontra na valorização do homem, por meio do aperfeiçoamento pessoal, cultural e técnico.

Segundo Azevedo (2008), um autor que aborda a questão do desenvolvimento com um viés semelhante ao de Sen é Martín, em que este salienta que o desenvolvimento se molda por meio do protagonismo de cada indivíduo. Essa premissa não difere do conceito de desenvolvimento local, já que este, conforme Abramovay (1998), pressupõe a participação de atores sociais. 
Dessa forma, a ideia do desenvolvimento local está no fortalecimento dos atores de um território, possibilitando-os de tirar benefícios das potencialidades locais, com fins a uma melhora na qualidade de vida. Assim, a participação local é um instrumento que possibilita um desenvolvimento equilibrado, além de promover um processo democrático na comunidade.

A participação local é uma forma de a sociedade reivindicar os benefícios da coletividade em prol de um comum. Essa medida é uma forma de capital social. Kliksberg (1999) salienta que o capital social acarreta fortalecimento social proporcionando desenvolvimento local. Para Putmam (1996, p. 177), "Capital social diz respeito a características da organização social, como confiança, normas e sistemas, que contribuam para aumentar a eficiência da sociedade, facilitando ações coordenadas".

Putmam (1996) ressalta que o capital social é produtivo, pois possibilita a realização de certos objetivos que seriam inalcançáveis se ele não existisse, além deste facilitar a cooperação mútua. $\mathrm{O}$ autor menciona que uma das características do capital social é a confiança, e esta promove a cooperação, visto que a própria cooperação promove a confiança. A partir do momento que se estimula a confiança, a má conduta é desestimulada. Ainda o referido autor menciona que a confiança pode originar duas fontes conexas e uma delas seriam os sistemas de participação cívica, em que o autor ressalta: "Os sistemas de participação cívica é uma forma essencial de capital social: quanto mais desenvolvidos forem esses sistemas numa comunidade, maior será a probabilidade de que seus cidadãos sejam capazes de cooperar em benefício mútuo" (PUTMAM, 1996, p. 183).

A atividade turística é acompanhada de discursos pautados no desenvolvimento que essa atividade pode trazer a uma localidade. Cabe destacar que tal desenvolvimento, na perspectiva do contexto teórico deste trabalho, só será alcançado quando ocorrer a incorporação da comunidade local no processo de planejamento e, mais ainda, em que esses atores sociais despertem para a importância da sua participação, aumentando assim o nível de civismo.

Dessarte, Azevedo (2008, p. 100) afirma que "nas regiões onde as comunidades cívicas participam ativamente da política, organizando-se em associações autóctones, incorporandosensos deresponsabilidade social e se imbuindo do espírito público, os avanços sociais são mais notórios”.

Entretanto a aliança do capital social à atividade turística em um determinado local, faz com que o processo de desenvolvimento nesse espaço não seja imposto de cima para baixo, mas, sim, respeitando as necessidades do local e o atendimento da prioridade deste, por meio do diálogo, possibilitando uma gestão mais horizontal e, de certa forma, vindo a colocar uma barreira aos aspectos impostos pela globalização, reforçando seu tecido social.

Diante da premissa de desenvolvimento e participação social, o Geoparque Seridó possui como pontochave, até mesmo para que a proposta seja aceita no âmbito do Programa da Unesco (Global Geoparks), a inserção da comunidade em suas atividades para promover o desenvolvimento. Esse desenvolvimento não é apenas na óptica economicista, vai mais, além disso. Dessa forma, um dos primeiros passos do Geoparque Seridó é sua apresentação à comunidade, de forma que esta entenda qual o objetivo do geoparque e como a sociedade pode ser inserida no contexto.

Nessa perspectiva, houve apresentações do projeto no ano de 2017 em Câmaras Municipais (a exemplo dos municípios de Currais Novos e Acari), abertas ao público e demais interessados para conhecer e entender em que consiste o Geoparque Seridó e os benefícios que este trará para as comunidades. Além do mais, outras medidas começaram a ser desenvolvidas e uma delas foi o apoio do governo do estado 
do Rio Grande do Norte, que vem fazendo discussões (no ano de 2017 ocorreram duas, uma em maio e outra em setembro), por meio de um Grupo de Trabalho para propor o regime jurídico para criação do geoparque. Esse Grupo de Trabalho foi instituído pelo Decreto n 24.488, de 05 de dezembro de 2016. O referido grupo conta com representantes de diversas áreas, entre eles: Universidade Federal e Estadual do Rio Grande do Norte, Secretaria de Estado de Turismo do RN, Empresa de Promoção Turística do Estado do RN, Procuradoria-Geral do Estado do RN, representantes dos seis municípios (Secretários) que compõem o geoparque, sem falar dos representantes das comunidades dos seis municípios.

O Geoparque Seridó foi apresentado em Feiras Internacionais de Turismo - FIT em Buenos Aires (Argentina), Berlim (Alemanha) e Portugal no ano de 2017, além das apresentações em simpósios e congressos científicos ou eventos específicos a cada município envolvido. Além disso, o geoparque estabeleceu parcerias com escolas nos municípios que contemplam a proposta, a exemplo do município de Currais Novos/RN, que em conjunto com a Escola Municipal Ausônio Araújo, os alunos visitaram os geossítios e desenvolveram trabalhos e oficinas que foram expostos à comunidade do local. No município de Carnaúba dos Dantas ações semelhantes junto aos alunos da rede municipal de ensino também ocorrem, principalmente nos geossítios onde ocorrem arte rupestre.

Além dessas ações, a comunidade pode ser incorporada ao geoparque por meio de atividades que estas já desenvolvam, como a prática de artesanato, atividade presente no Seridó, venda de comidas regionais, como queijo, manteiga, queijo de coalho, carne de sol, além de outras atividades, como agricultura, pecuária e mineração, caracterizando, muitas vezes, um geoproduto, apresentando assim sua identidade cultural.

Assim, todo dinheiro angariado com a venda dos produtos será revertido aos próprios vendedores, a exemplo do que já acontece em Carnaúba dos Dantas no geossítio Xique-Xique, cujo dinheiro arrecadado com a cobrança da entrada no local é revertido para os proprietários do local, além de venderem aos visitantes água mineral, bolo, suco e dindim. Além dos benefícios econômicos, a partir do momento que esses atores se articulam para o processo de tomada de decisões, inicialmente das pautas de assuntos referentes ao geoparque, promoveria um engajamento desses atores sociais e estimularia o processo de participação no âmbito do geoparque.

A partir dessa articulação, paulatinamente será reforçada a cooperação entre eles para o desenvolvimento das atividades, e essa cooperação, conforme colocado por Putmam, iria reforçar o capital social no âmbito do geoparque. A partir do momento que ocorrer o fortalecimento desse capital social, este iria se reverberar para outros aspectos da coletividade no tocante a esse grupo, podendo a vir interferir nos outros atores que não estejam inseridos diretamente com a sistemática do geoparque, e esses cidadãos despertariam um maior interesse em participar de aspectos seja na esfera econômica, social e cultural, e mesmo que não lhes fosse dada a oportunidade, tal pressão, desses atores com nível de conhecimento da importância de participação, afetaria o modo como são executadas as atividades dentro do contexto do Seridó. 
E esse capital social ainda seria mais fortalecido, pois como afirma Azevedo (2008, p. 100):

No Seridó potiguar as redes sociais encontram-se estabelecidas por meio de vínculos familiares e de laços de compartilhamento e de solidariedade, liames de confiança, laboriosidade e outros atributos culturais através da constituição ampla e efetiva de sistemas horizontais de participação, onde a coletividade e a reciprocidade suplantem os vínculos clientelistas e os territórios conservadores de poder.

Além do mais, o fortalecimento do capital social no âmbito do geoparque, reverberado para a sociedade, culminaria no fortalecimento dos atores sociais, concordando com a premissa de Kliksberg (1999) quando salienta que o capital social acarreta fortalecimento social proporcionando desenvolvimento local.

Diante de tal cenário, o geoparque pode vir a ser um meio no qual os atores sociais, que participarão das atividades desenvolvidas no âmbito deste, serão estimulados a participarem das reuniões e pautas do projeto. Assim, os atores reforçarão a importância de se fazer presentes em um processo de participação. Logo, por meio da participação, elencariam suas necessidades e assim fortaleceriam o capital social presente dentro do geoparque.

Tal mudança de comportamento pode impactar no estímulo de participar das articulações em seus municípios e vindo a fortalecer o capital social destes, resultando em uma nova articulação social em prol de um desenvolvimento mais além da economicista.

\section{CONSIDERAÇÕES FINAIS}

Mesmo diante de um cenário em que o Estado é utilizado para obtenção de interesse específico em detrimento do interesse coletivo, assim como comunga a óptica marxista, a formulação de uma política pública é um importante instrumento norteador das ações do Estado. A articulação das diretrizes e ações nos diferentes setores permitem que o Estado aja regulando os interesses em virtude de uma coletividade.

O turismo, caracterizado mais por seus efeitos econômicos, e foram esses impactos econômicos que resultaram na importância de formulação de políticas públicas para a atividade, demonstra a importância das políticas como um instrumento de regulação para a atividade.

O projeto Geoparque Seridó é uma dinâmica nova que ocorre nos territórios, por ser uma nova forma de gestão territorial em que elementos do patrimônio geológico, a cultura, a história, a gastronomia e o turismo podem ser desenvolvidos de forma holística resultando em uma ação participativa que integre a população. Por meio desse projeto que permite a inserção da comunidade em suas ações, a população é estimulada a exercer seu poder participativo no processo de construção das ações no âmbito do geoparque, pois esse processo dialético se faz necessário para viabilização do geoparque no âmbito do novo programa da Unesco (Global Geoparks).

Assim, o processo participativo proposto pelo geoparque fortalece os aspectos cívicos da comunidade seridoense presente no território do geoparque, permite a construção e reforço dos elementos de confiança no território e, consequentemente, fortalece seu capital social que culmina em um processo de desenvolvimento mais democrático.

Todo esse processo participativo não deixa de ser um meio de construção de conhecimento desses atores sociais, no sentido de como a articulação de uma comunidade pode refletir seus interesses e mudar 
a sua realidade. É dessa forma que o Geoparque Seridó pode vir a ser uma grande contribuição para o início de todo esse processo e assim reverberar para a expansão das liberdades desses mesmos atores sociais.

\section{REFERÊNCIAS}

ABRAMOVAY, R. A formação do capital social para o desenvolvimento sustentável. São Luiz: CONTAG. II Fórum de Cooperação Técnica. 1998.

ALVES, M. L. Religiosidade, Turismo e Cultura na região do Seridó-RN. XIII Congresso Brasileiro de Sociologia, 29 de maio a 1 de junho de 2007, UFPE, Recife/PE. 2007.

AZEVEDO, F. F. et al. (Org.). Turismo em foco. Belém: NAEA. 2013.

AZEVEDO, F. F. Desenvolvimento Local e Capital Social: uma abordagem teórica. Aracaju: Revista Geonordeste, Ano XIX, 1, p. 87-105, jul. 2008.

BENI, M. C. Política e planejamento de turismo no Brasil. São Paulo: Aleph, 2006.

BOBBIO, N. A teoria das formas de governo. 5. ed. Brasília: Editora Universidade de Brasília, 1988.

COSTA, M. M.; REIS, S. da S. Cidadania, participação e capital social na gestão de políticas públicas. 2010. Disponível em: 〈http://online.unisc.br/seer/index.php/direito/article/view/1180〉. Acesso em: 2 jun. 2015.

COUTINHO, A. C. Políticas públicas, desenvolvimento local e participação social nas instâncias de governança associadas ao turismo no Rio Grande do Norte. Dissertação de Mestrado, PPGTUR/UFRN. Natal: Brasil, 2015.

CRUZ, R. C. Políticas Públicas de turismo no Brasil: território usado, território negligenciado. Geosul. Florianópolis, v. 20, n. 40, p. 27-43, jul/dez 2005.

FARSANI, N. T.; COELHO, C.; COSTA, C. Geoparks as Art Museums for Geotourists. Revista Turismo e Desenvolvimento, v. 2, n.13, p. 173-182, 2010.

FERREIRA, É. S.; PESSOA, V. L. Capital social e desenvolvimento territorial: uma abordagem teóricoconceitual. Campo-território: Revista de Geografia Agrária, v. 7, n.14, p. 1-33, ago. 2012.

FREY, K. Políticas Públicas: um debate conceitual e reflexões referentes à prática da análise de políticas públicas no Brasil. Planejamento e Políticas públicas. n. 21, p. 211-259, ago. 2000.

GALDINO, L. C.; COSTA, M. L. Análise das principais políticas públicas de turismo no Brasil, da década de 1990 à atualidade. Observatório de Inovação de Turismo - Revista Acadêmica, v. 4, n. 4, p. 1-24, set. 2011.

GOELDNER, C. R.; RITCHIE, J. R. B.; MCINTOSH, R. W. Turismo: princípios, práticas e filosofias. 8. ed. Porto Alegre: Bookman, 2002.

HÖFLING, E. M. Estado e políticas (públicas) sociais. Cadernos Cedes, ano XXI, n. 55, nov. 2001.

KLIKSBERG, B. Capital social y cultura. Claves olvidades del desarrallo. Coordinada del Instituto Interamericano para el Desarrollo Social (INDES/BID), 1999. 
LIMA, R. A. Notas sobre a teoria do Estado em Marx. 2009. Disponivel em: 〈http://www.ifch.unicamp. $\mathrm{br} /$ formulario_cemarx/selecao/2009/trabalhos/notas-sobre-a-teoria-do-estado-em-marx.pdf〉. Acesso em: 2 jun. 2015.

MARX, K.; ENGELS, F. Manifesto do Partido Comunista. In: REIS FILHO, D. A. 0 manifesto comunista 150 anos depois. Rio de Janeiro: Contraponto; São Paulo: Fundação Perseu Abramo, 1998.

MAX-NEEF, M. A. Desarollo a escala humana: conceptos, aplicaciones y algunas reflexiones. Montevideo: Icaria, 1993.

MEDEIROS, J. L.; NASCIMENTO, M. A. L.; PERINOTTO, A. R. C. Práticas turísticas por meio da análise da dimensão ambiental em geossítios do Projeto Geoparque Seridó (RN). Revista Brasileira de Ecoturismo, v. 10, n. 3, p. 552-578, ago/out. 2017.

MOREIRA, J. C. Geoturismo e Interpretação Ambiental. Ponta Grossa: editora UEPG. 2014.

NASCIMENTO, M. A. L. do; GOMES, C. S. C. D.; SOARES, A. dos S. Geoparque como forma de gestão territorial interdisciplinar apoiada no geoturismo: caso do Projeto Geoparque Seridó. Revista Brasileira de Ecoturismo, v. 8, n. 2, p. 347-365, mai/ago. 2015.

NICKOLAS, Z. The European Geoparks Network Geological heritage protection and local development. Episodes, v. 27, n. 3, p. 165-171, set. 2004.

OLIVEIRA, F. O. Política e Estado no Pensamento Marxista. 2006. Disponível em: 〈https://georisk. wikispaces.com/file/view/Pol\%C3\%ADtica+e+Estado+no+pensamento+marxista〉. Acesso em: 22 mai. 2015.

PEREIRA, L. C. Estado, Sociedade Civil e Legitimidade democrática. Lua Nova, n. 36, p. 85-200, 1995.

POULANTZAS, N. Poder político e classes sociais. 2. ed. São Paulo: Martins Fontes.1986.

PUTNAM, R. D. Comunidade e democracia: a experiência da Itália moderna. Rio de Janeiro: FGV. 1996.

RESENDE, F. M.; DIÓGENES, E. M. Estado, classes sociais e políticas públicas. III JORNADA INTERNACIONAL DE POLÍTICAS PÚBLICAS - São Luís - MA, 28 a 30 de agosto de 2007.

SACCOI, A. P. A concepção de Estado no pensamento de Durkheim: lições de sociologia. Revista Eletrônica dos pós-graduandos em sociologia política da UFSC, v. 9. n. 1, p. 96-102, jan/Jul 2012.

SCHOBBEnHAUS, C.; SILVA, C. R. da. Geoparques do Brasil: propostas. v. 1. Companhia de Pesquisa de Recursos Minerais - CPRM, 2012.

SEN, A. K. Desenvolvimento como liberdade. Tradução de Laura Teixeira Motta. 4. Reimp. São Paulo: Brasil, 2000.

SOUZA, C. Estudo da Arte da área de Políticas Públicas: conceitos e principais tipologias. XXVII Encontro Anual da Associação Nacional de Pós-Graduação e Pesquisa em Ciências Sociais (ANPOCS). 2003.

SOUZA, J. M. Estado e sociedade civil no pensamento de Marx. Serv. Soc. Soc., São Paulo, n.101, p. 25-39. Jan/Mar. 2010.

TABOSA, F. J. et al. Desenvolvimento local e capital social: uma leitura sobre os núcleos e arranjos produtivos do estado do Ceará. Disponível em: 〈http://www.sober.org.br/palestra/12/05P308.pdf〉. Acesso em: 10 jun. 2015. 
TEIXEIRA, E. C. 0 Papel das Políticas Públicas no Desenvolvimento Local e na Transformação da Realidade. 2002. Disponível em: 〈http://www.dhnet.org.br/dados/cursos/aatr2/a_pdf/o3_aatr_ pp_papel.pdf.> Acesso em: 20 mai. 2015.

VIDAL, F. B. 0 estado e as políticas públicas no período regressivo do capitalismo. 2011.

WEISS, R. H. Políticas Públicas no setor de turismo: utopia ou realidade? Dissertação de Mestrado. FGV. Rio de Janeiro. 2000. 